\title{
Galectin 3 in heart failure
}

\author{
Viroj Wiwanitkit
}

Received: 7 February 2010/Accepted: 29 March 2010/Published online: 7 April 2010

(C) Springer-Verlag 2010

\section{Editor,}

I read the report on galectin 3 in heart failure by Lok et al. [1] with great interest. Lok et al. concluded that "Its prognostic value is independent of severity of $\mathrm{HF}$, as assessed by NT-proBNP levels, and it may potentially be used in the management of such patients [1]." Based on the study of Lok et al. [1], galectin 3 seems to be a good biomarker. However, there are some facts on the galectin 3 determination to be concerned. First, the level of galectin 3 can be deviated in case with underlying concomitant thyroid disorder [2]. In addition, its increased level is also mentioned for many other neoplasms and inflammations [3]. In the report by Lok et al., these other possible concomitant disorders were not completely ruled out. Second, the laboratory quality control is an important issue to be discussed. Interference in sample collection and laboratory analysis should be carefully managed.

\section{References}

1. Lok DJ, Van Der Meer P, de la Porte PW, Lipsic E, Van Wijngaarden J, Hillege HL, van Veldhuisen DJ (2010) Prognostic value of galectin-3, a novel marker of fibrosis, in patients with chronic heart failure: data from the DEAL-HF study. Clin Res Cardiol. 2010 Feb 4 [Epub ahead of print]

2. Kim MJ, Kim HJ, Hong SJ, Shong YK, Gong G (2006) Diagnostic utility of galectin-3 in aspirates of thyroid follicular lesions. Acta Cytol 50(1):28-34

3. Henderson NC, Sethi T (2009) The regulation of inflammation by galectin-3. Immunol Rev 230(1):160-171

V. Wiwanitkit $(\bowtie)$

Wiwanitkit House, Bangkhae, Bangkok 10160, Thailand

e-mail:wviroj@yahoo.com 